\title{
VEREDAS DO TRIÂNGULO MINEIRO: SOLOS, ÁGUA E USO
}

\author{
Veredas of Minas Gerais Triangle: soils, water and use
}

\author{
Marcus Vinícius Vieitas Ramos ${ }^{1}$, Nilton Curi², Paulo Emílio Ferreira da Motta ${ }^{3}$, \\ Antonio Carlos Tadeu Vitorino ${ }^{4}$, Mozart Martins Ferreira ${ }^{2}$, Marx Leandro Naves Silva ${ }^{2}$
}

\begin{abstract}
RESUMO
Sendo as veredas importantes reguladores do equilíbrio dos cursos d'água da região dos cerrados, objetivou-se caracterizar e comparar solo, água e tipo de uso destes ambientes nas superfícies geomórficas Chapadas e Arenito Bauru. Foram coletadas amostras dos solos e da água, das veredas. $\mathrm{O}$ uso foi analisado por observações de campo e entrevistas com proprietários rurais. As veredas apresentam solos hidromórficos em toda a sua extensão, havendo maior homogeneidade no Bauru. Do terço superior em direção ao terço inferior, a drenagem piora, e são maiores os teores de argila, matéria orgânica e fertilidade natural. As veredas do Bauru apresentam melhor drenagem, maior fertilidade, menores teores de matéria orgânica de argila. A água enquadrou-se na classe 4, principalmente em função da cor, acompanhando variações do teor de matéria orgânica do solo. Nas veredas da Chapada, o uso da água na agricultura gera risco de contaminação ambiental, enquanto no Bauru, é comum seu represamento para dessedentação do gado. Os solos das veredas do Bauru são utilizados com frequiência para pastagem nativa, os da Chapada, são mantidos sem uso. A cor preta ou cinzenta dos solos é um atributo de fácil identificação no campo para delimitar tais ambientes.
\end{abstract}

Termos para indexação: Ambiente, nascentes, cerrado, solos hidromórficos.

\section{ABSTRACT}

Being the veredas (swampy plains between hills and rivers) important regulators of water courses equilibrium at the cerrado region, we aimed to characterize and to compare soils, water and use type of these environments in Chapada and Arenito Bauru geomorphic surfaces. Soil and water samples were collected from the veredas. The use was analysed through field observations and interviews with farmers. The veredas present hydromorphic soils in all their extension, occurring higher homogeneity in Bauru. From the superior to the inferior part, the drainage gets worse, and the clay contents, organic matter and natural fertility increase. The Bauru veredas present better drainage, higher natural fertility, smaller amounts of organic matter and clay.The water was classified as class 4, mainly as a function of color, following variations in the soil organic matter content. At Chapada veredas, the water use in agriculture generates environmental contamination risk, while at the Bauru ones, it is common the water damming up for cattle supplying. The soils of Bauru veredas are frequently used for native pasture, while the Chapada ones are maintained without use. The black or grayish color of the veredas soils is an easily-identifiable field attribute for delimitation of such environments.

Index terms: Environment, springs, cerrado, hydromorphic soils.

(Recebido para publicação em 11 de janeiro de 2005 e aprovado em 25 de janeiro de 2006)

\section{INTRODUÇÃO}

O domínio morfoclimático do cerrado é caracterizado por chapadões cobertos por vegetação de cerrado e penetrado por floresta-galeria ao longo dos cursos d'água (AB'SÁBER, 1971). Dentro deste domínio, nos cerrados do Brasil Central, é típica a presença de veredas (EMBRAPA, 1975, 1982), ambiente definido genericamente como tendo uma importante vegetação arbórea-arbustiva na parte central, onde se destaca a palmeira buriti (RESENDE et al., 1985).

As veredas são subsistemas úmidos que participam do controle do fluxo do lençol freático, desempenhando um papel fundamental no equilíbrio hidrológico dos cursos d'água no ambiente do cerrado. Constitui-se num sistema represador da água armazenada na chapada, sendo importante para a perenização dos córregos, ribeirões e até mesmo dos rios, a jusante destes sistemas. Representam também um ambiente de grande relevância dentro do cerrado, por serem responsáveis pela manutenção e multiplicação da fauna terrestre e aquática. Esses ambientes, entretanto, são sensíveis à alteração e de pouca capacidade regenerativa, quando perturbados (CARVALHO, 1991).

Apesar do importante significado das veredas para o cerrado, existem poucas pesquisas sobre as mesmas. Freyberg (1932), citado por Barbosa (1967), Boa Ventura (1978) e Lima (1996) estudaram a formação e evolução das veredas. Melo (1978) caracterizou veredas no contexto geomorfológico. Melo (1992) também caracterizou aspectos morfológicos e evolutivos das veredas. Amaral (1999),

\footnotetext{
${ }^{1}$ Engenheiro Agronômo, M.Sc.-mramos@unb.br

2 Engenheiro Agronômo, Professor do Departamento de Ciência do Solo - Universidade Federal de Lavras/UFLA - Cx. P. 3037 - $37200-000$ - Lavras, MG.

${ }^{3}$ Engenheiro Agronômo, Pesquisador Embrapa-Solos - motta@cnps.embrapa.br

${ }^{4}$ Engenheiro Agrônomo, Professor do Departamento de Ciências Agrárias - Universidade Federal do Mato Grosso do Sul/UFMS - Cx. P. 533 - 79804-970 Dourados, MS - acvitor@ceud.ufms.br
} 
Embrapa (1982), Ribeiro \& Walter (1998) caracterizaram a vegetação das veredas. Quanto aos solos, algumas descrições de perfis foram realizadas por Amaral (1999), Corrêa (1989), Couto et al. (1985), Embrapa (1976, 1978, 1982, 1986) e Epamig (1978).

Mesmo regionalmente, as veredas podem apresentar-se sob diferentes condições ambientais. No Triângulo Mineiro, as veredas ocorrem em grande densidade, em diferentes superfícies geomórficas. Nesta região, cada superfície geomórfica representa um ambiente peculiar, implicando em atributos diferenciais de seus recursos naturais, padrões de uso e resistência à perturbação.

Diante destas circunstâncias, objetivou-se com o presente trabalho caracterizar os solos dos ambientes de vereda das Chapadas e do Arenito Bauru, no Triângulo Mineiro; determinar alguns atributos relacionados à qualidade da água dos ambientes de vereda estudados; comparar o uso destes ambientes; e sugerir algum atributo de fácil identificação no campo que possa ser utilizado para delimitar tais ambientes.

\section{MATERIAL E MÉTODOS}

O Triângulo Mineiro foi escolhido para o estudo por ser uma região representativa do cerrado, que apresenta intensa atividade agropecuária e grande densidade de veredas. Com base no conhecimento da região e com o apoio do Levantamento de Solos do Triângulo Mineiro (EMBRAPA, 1982), foram realizadas viagens de campo para reconhecimento dos ambientes de vereda, característicos da região.
Foram selecionadas veredas de duas diferentes superfícies geomórficas (expressão usada em estudos de relação solo-paisagem, significando porções da paisagem especificamente definidas no espaço e no tempo, RUHE, 1969): da $1^{\underline{a}}$ superfície (para brevidade na discussão, esta será referida como Chapada e da $2^{\underline{a}}$ superfície (assim como no caso da $1^{\mathrm{a}}$ superfície, para brevidade na discussão, esta será referida como Arenito Bauru). Estas duas superfícies foram escolhidas por apresentarem-se bem definidas na paisagem, possuírem maior densidade de veredas, quando comparadas com as demais superfícies que ocorrem na região, apresentarem diferenças entre si quanto aos solos e material de origem (Figura 1), e por possuírem diferentes padrões de uso da terra.

A superfície geomórfica da Chapada apresenta clima Cwa da classificação de Köppen. Este clima caracteriza-se por ser temperado suave (mesotérmico), chuvoso, com inverno seco. Apresenta a temperatura média do mês mais frio entre -3 e $18^{\circ} \mathrm{C}$ e a do mês mais quente superior a $22^{\circ} \mathrm{C}$ (EMBRAPA, 1982). Esta superfície corresponde às áreas elevadas com topos planos e amplos, e vales pouco profundos, espaçados e com pouca ramificação de drenagem. A altitude desta superfície varia de 850 a 1000 metros (EMBRAPA, 1982). Geologicamente, enquadram-se como remanescentes de cobertura constituídos de material referente ao Terciário (BACCARO, 1994). Os solos são predominantemente Latossolos de textura muito argilosa, ocorrendo uma área expressiva de solos hidromórficos próxima aos canais fluviais (BACCARO, 1994; EMBRAPA, 1982).

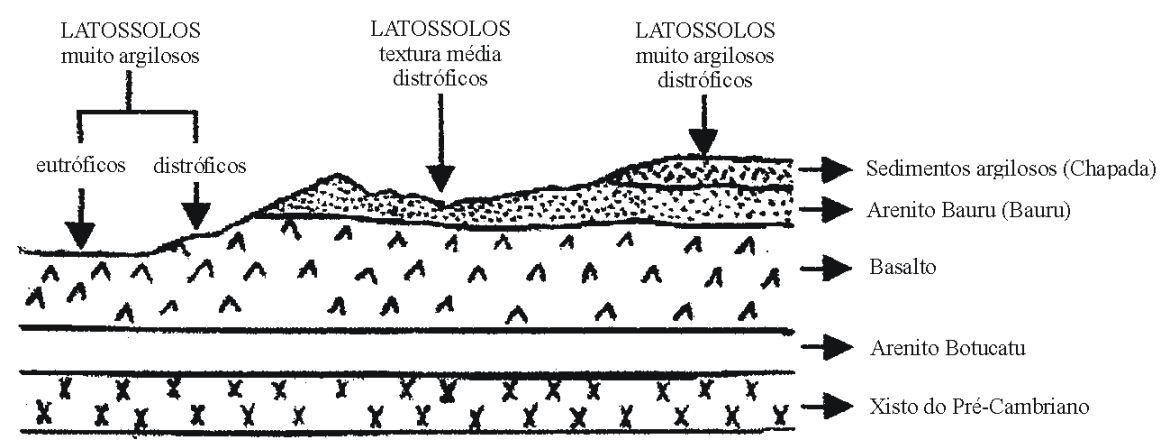

FIGURA 1 - Distribuição esquemática dos solos predominantes na paisagem do Triângulo Mineiro. Fonte: Resende (1976). 
A superfície do Bauru apresenta clima Aw. Este clima caracteriza-se por ser tropical chuvoso (clima de savana), megatérmico, com inverno seco. A temperatura do mês mais frio é superior a $18^{\circ} \mathrm{C}$ e a precipitação do mês mais seco é inferior a $60 \mathrm{~mm}$ (EMBRAPA, 1982). É constituída por topos aplainados de vertentes suaves, interrompidas por rupturas locais. Sua altitude varia de 700 a 900 metros. O componente litológico predominante é o arenito do Grupo Bauru. Esta área é recoberta principalmente por Latossolos de textura média. Os solos hidromórficos são encontrados em muitos fundos de vales, bem como em áreas de surgência (BACCARO, 1994).

A partir das observações de campo, foram escolhidas 6 veredas para o estudo, sendo 3 na $1^{\text {a }}$ superfície (Chapada) e as demais na $2^{\text {a }}$ superfície (subsistema do Arenito Bauru). As veredas estudadas situam-se entre

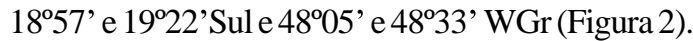

Os solos foram estudados ao longo de um caminhamento perpendicular às linhas de drenagem das veredas, sendo que em cada vereda descreveu-se uma seqüência. Foram selecionados três perfis de solo por vereda.

Para a descrição e identificação dos solos, foi utilizado o terço inferior, terço médio e terço superior das veredas. A descrição dos solos baseou-se nas normas preconizadas por Lemos \& Santos (1996). Os solos foram classificados com base no Sistema Brasileiro de Classificação de Solos (EMBRAPA, 1999). A partir da descrição morfológica, amostras compostas para análises físicas, químicas e mineralógicas foram coletadas em profundidades variáveis, em função dos limites dos distintos horizontes reconhecidos.

Para a determinação da qualidade da água do lençol freático, foram coletadas amostras, em frascos de vidro âmbar previamente lavados em laboratório, que posteriormente foram armazenadas em condições de resfriamento, até serem encaminhadas para o laboratório, obedecendo as recomendações do guia de coleta e armazenamento de água da CETESB (1988).

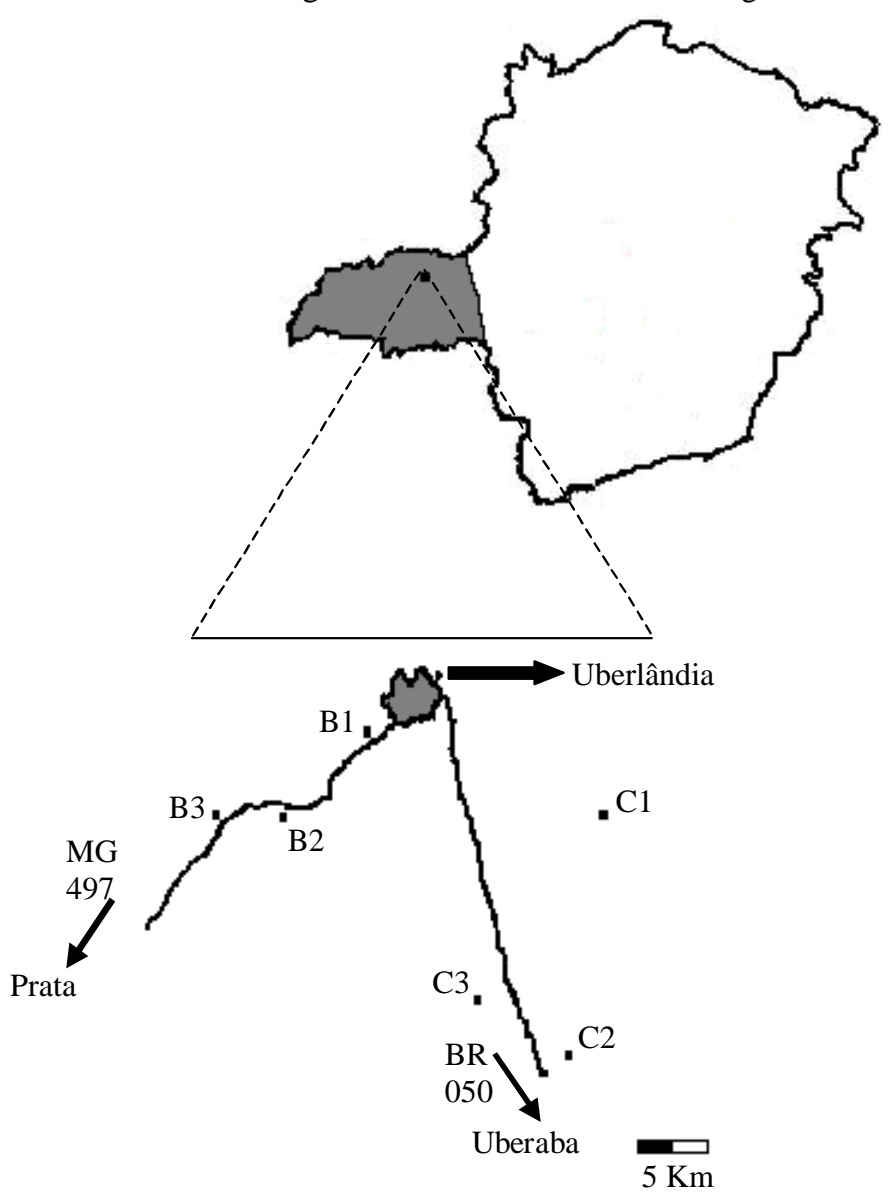

FIGURA 2 - Posicionamento das veredas da Chapada (C1, C2, C3) e do Bauru (B1, B2, B3). 
Para a investigação do histórico de uso, qualidade dos recursos naturais, alterações deste ambiente e problemas enfrentados pelos agricultores, foi utilizada a técnica da convergência descrita por Resende (1983), que consiste basicamente na realização de uma bateria de entrevistas informais com os agricultores, utilizando as mesmas como ferramentas para obtenção de informações. No presente estudo foram entrevistados vinte proprietários rurais, sendo dez de cada ambiente.

As amostras de solo, após secas ao ar, foram peneiradas, sendo a fração menor que $2 \mathrm{~mm}$ submetida às análises. A análise granulométrica foi realizada pelo método da pipeta, segundo Day (1965). Nas amostras com teor de matéria orgânica maior que 5\%, utilizou-se, como prétratamento, o ataque com peróxido de hidrogênio $\left(\mathrm{H}_{2} \mathrm{O}_{2}\right)$ $30 \%$.

As análises do complexo sortivo $(\mathrm{Ca}, \mathrm{Mg}, \mathrm{Ke} \mathrm{Al})$ e P disponível, foram realizadas segundo Vettori (1969), com modificações de Embrapa (1979, 1997). P (Resina) e carbono orgânico foram determinados segundo Raij et al. (1987).

Foram selecionadas amostras dos solos mais representativos em cada posição da paisagem, para análise mineralógica. As amostras da fração argila desferrificada foram submetidas à difração de raios-X (DRX) (KLUG \& ALEXANDER, 1974).

Os atributos da água das veredas analisados foram: odor (por aquecimento); condutividade (pelo condutivímetro); turbidez (pelo turbidímetro); sólidos totais (secagem e pesagem); teores de ferro, cálcio, magnésio, zinco e manganês (por meio de absorção atômica); e as demais análises foram feitas por titulometria. Realizaram-se as análises de acordo com o APHA (1989). Os resultados obtidos foram avaliados segundo os padrões de qualidade para os corpos d'água (Resolução CONAMA $\left.\mathrm{n}^{\circ} 20,18 / 10 / 86\right)$.

\section{RESULTADOS E DISCUSSÃO}

\section{Solos das veredas}

Os solos das veredas da Chapada apresentaram, de uma maneira geral, atributos físicos, químicos e mineralógicos diferentes dos solos das veredas do Bauru. Estas diferenças possivelmente estão ligadas a fatores como: origem dos sedimentos, influência do nível de estabilidade do lençol freático, intensidade de deposição de sedimentos nas veredas e a própria ação antrópica.

As veredas das diferentes superfícies geomórficas estudadas apresentam, como aspecto comum, a ocorrência de solos hidromórficos em toda a sua extensão transversal
(Figura 3). Nas veredas da Chapada, há uma tendência de mudança gradativa dos solos do terço inferior em direção ao terço superior da vereda, a saber: Organossolos Mésicos, Gleissolos Melânicos e Gleissolos Háplicos. Nas veredas do Bauru, predominam Gleissolos em todos os segmentos da paisagem. Possivelmente, a maior caixa de armazenamento de água na Chapada, que permite manter mais estável o nível do lençol freático nas suas veredas (justificando a ocorrência do Organossolo neste ambiente) venha a se constituir em importante fator responsável pela sua maior variabilidade de classes de solos ocorrentes.

A matéria orgânica apresenta-se como uma grande contribuidora para a fase sólida dos solos do terço inferior das veredas de ambas as superfícies, mas principalmente no terço inferior das veredas da Chapada (Figura 4), em função da menor aeração. A composição granulométrica dos solos das veredas é bem distinta entre os ambientes estudados. Nas veredas da Chapada, os solos são, em média, de textura muito argilosa, enquanto na superfície do Bauru, de acordo com a posição na vereda, os solos variam de textura muito argilosa a argilosa no terço inferior, argilosa no terço médio e média no terço superior. A presença de solos mais argilosos nos terços médio e inferior destas veredas possivelmente está associada ao lento transporte de material mais fino em suspensão das partes mais altas da paisagem local.

Os maiores teores de matéria orgânica foram registrados nos solos das veredas das Chapadas. A maior caixa de armazenamento de água na Chapada propiciando uma maior estabilidade do nível do lençol freático, aliado ao maior distrofismo destes ambientes, representado pelos menores valores de soma de bases e maiores de saturação por alumínio (Figura 5), além da temperatura mais fria, devem ser os fatores determinantes do maior acúmulo de matéria orgânica nestes ambientes.

Nas veredas, a soma de bases é maior no terço inferior, onde são mantidas por reciclo e concentradas pela maior evapotranspiração, reduzindo-se em direção ao terço superior. Os solos das veredas do Bauru, quando comparados com os das veredas da Chapada, apresentamse com uma maior soma de bases em todas as posições da paisagem. $\mathrm{O}$ terço inferior desta superfície atinge valores de soma de bases considerados muito bons (ALVAREZ et al., 1999). Concentrações de bases mais elevadas nas veredas do Bauru são explicadas pela ocorrência de uma fonte de sedimentos mais rica nesta superfície (EMBRAPA, 1982). Segundo Resende et al. (1999), o sedimento argiloso que deu origem aos solos da Chapada é quimicamente mais pobre que o material psamítico da superfície do Bauru.

Ciênc. agrotec., Lavras, v. 30, n. 2, p. 283-293, mar./abr., 2006 


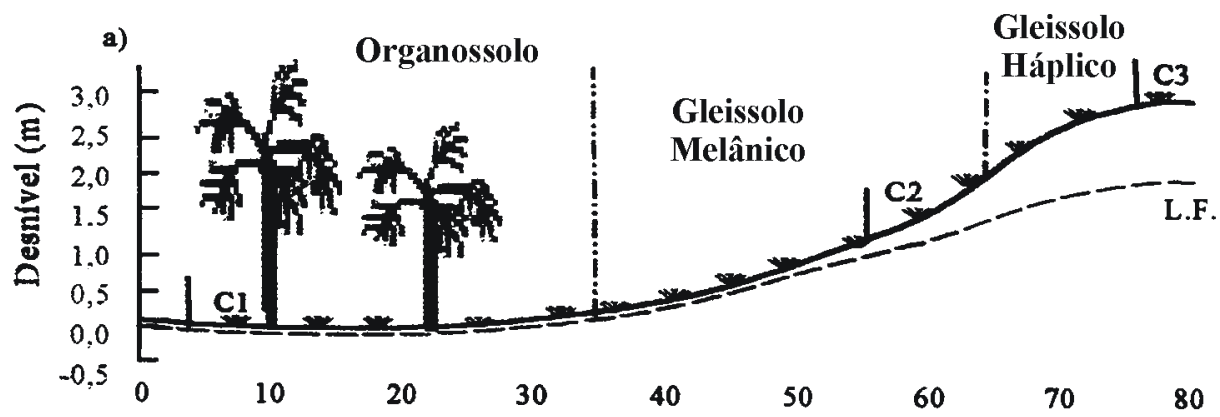

Distância do talvegue (m)

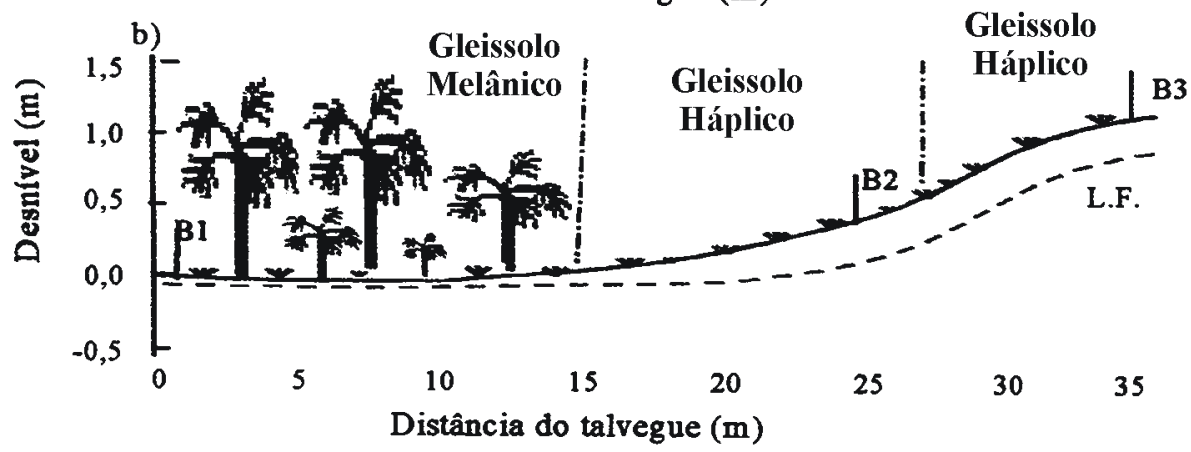

FIGURA 3 - Corte esquemático mostrando a topografia, distribuição e profundidade do lençol freático (L.F.) e a seqüência predominante de classes de solos constatadas nas veredas da Chapada (a) e do Bauru (b).

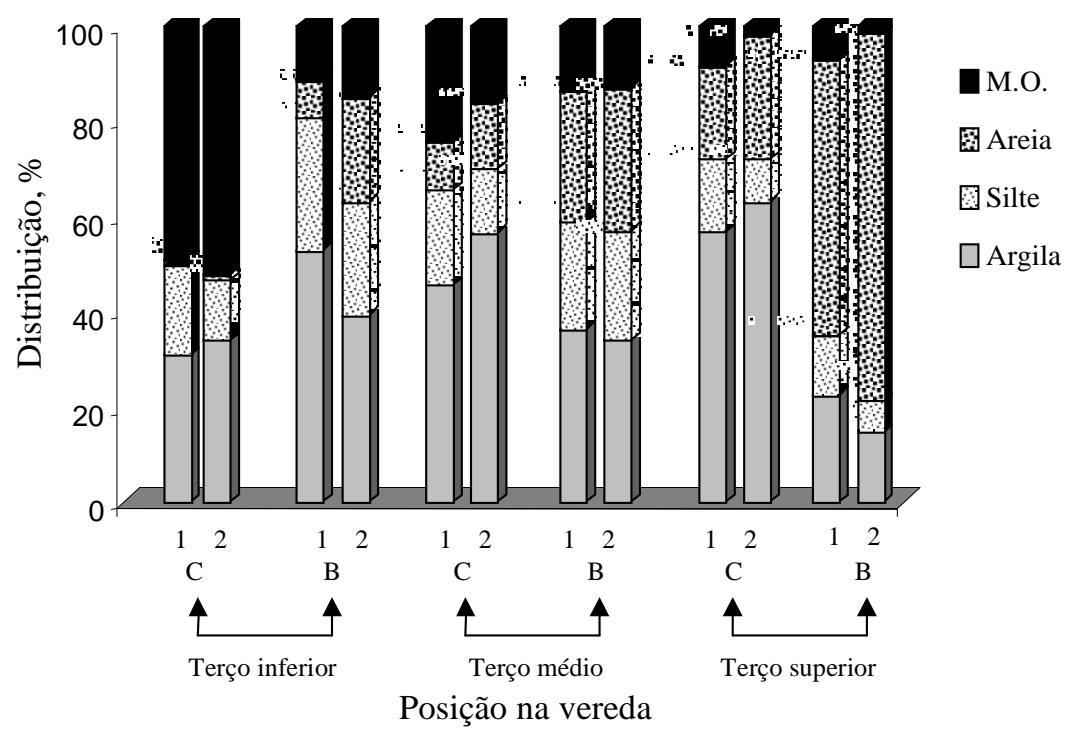

FIGURA 4 - Composição média da fase sólida dos solos das veredas da Chapada (C) e do Bauru (B) nas camadas superficial (1) e subsuperficial (2) nas diferentes posições das veredas. 
Chapada $\square$ Bauru
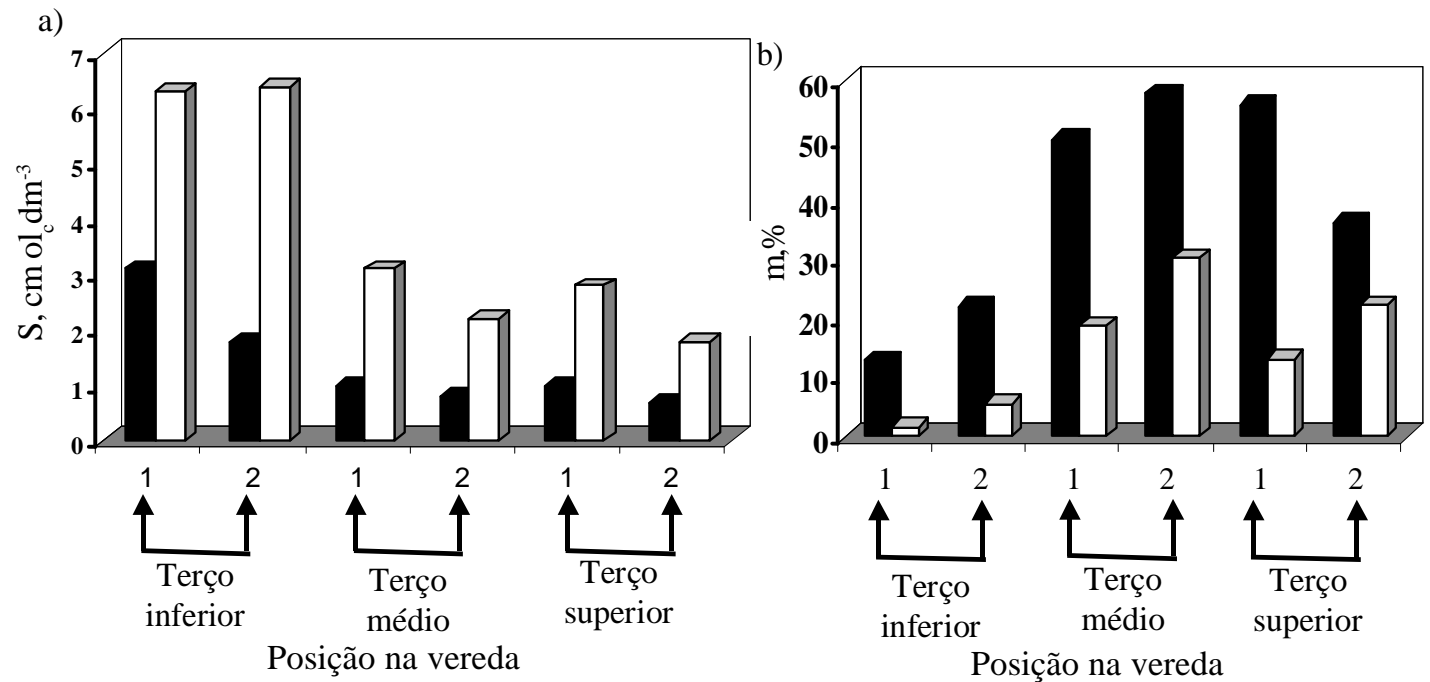

FIGURA 5 - Valores médios de soma de bases (Valor S) (a) e de saturação por Al (Valor m) (b) dos solos da Chapada e do Bauru, nas camadas superficial (1) e subsuperficial (2) nas diferentes posições das veredas.

O P-resina apresenta valores mais elevados em todas as posições das veredas em relação ao extrator Mehlich-1 (Figura 6), o que está de acordo com Grande et al. (1986). Nas veredas da Chapada, o teor de P é geralmente maior que nas do Bauru. O modelo de agricultura mais intensiva na região da Chapada favorece o maior acúmulo de $\mathrm{P}$ nesta superfície pela utilização massiva de insumos.

Nos solos das veredas da Chapada, a difração de raios-X da fração argila desferrificada revelou caulinita, gibbsita, mica, vermiculita com hidróxi-Al entrecamadas (VHE), cristobalita ( $\mathrm{Cb})$, anatásio e quartzo. No caso do Bauru, não foram constatadas VHE e Cb (difratogramas não apresentados). As prováveis explicações para a ausência de VHE nos solos das veredas da Chapada são: (a) maior ocorrência deste argilomineral nos Latossolos mais argilosos desta superfície; (b) maior concentração de Al nos solos das veredas das Chapadas, contribuindo para uma maior estabilização da vermiculita; e (c) maior influxo de sílica nas veredas da Chapada.

\section{Água das veredas}

O estudo físico-químico da água do lençol freático teve como objetivo apresentar uma caracterização preliminar da qualidade das águas do lençol freático das veredas e compará-las, investigando possíveis relações com atributos dos solo.

De acordo com os padrões de qualidade para corpos d'água (Resolução CONAMA n $\left.{ }^{0} 20,18 / 06 / 86\right)$, citada por Sperling (1996), a água foi enquadrada na classe 4 (Tabela 1), podendo ser destinada, portanto, a usos menos exigentes, tal como a harmonia paisagística.

$\mathrm{O}$ atributo que mais interferiu na qualidade foi a cor, atingindo valores de coloração bastante altos, destacando-se as veredas da Chapada (Tabela 1).

Em condições naturais, a matéria orgânica (ácidos húmicos e fúlvicos), ferro e manganês são os elementos que mais interferem na cor da água (SPERLING, 1996). No presente estudo, a origem destes altos valores de cor está associada principalmente com os altos teores de matéria orgânica na água, constatados pelos valores de oxigênio consumido (indicador indireto do teor de matéria orgânica na água), provenientes dos solos de natureza hidromórfica (Tabela 2). Os teores de ferro também influenciaram na cor da água, porém, o ferro não se apresentou como fator predominante para a determinação da cor, já que os valores mais altos de cor foram obtidos na água das veredas da Chapada, onde o teor de ferro na solução foi menor. 

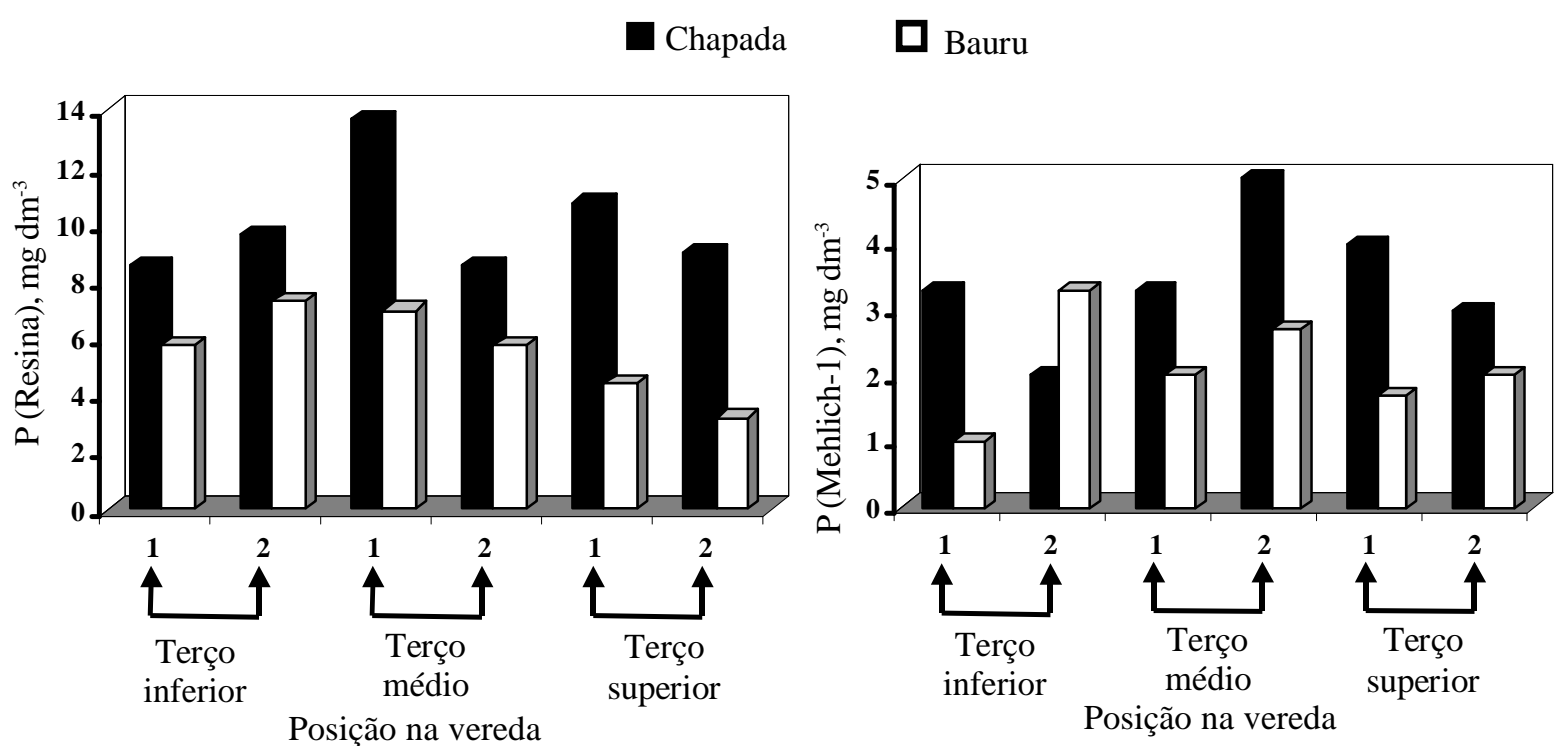

FIGURA 6 - Teores médios de fósforo dos solos da Chapada e do Bauru, nas camadas superficial (1) e subsuperficial (2) nas diferentes posições das veredas, por diferentes extratores.

TABELA 1 - Atributos físico-químicos (valores médios) da água do lençol freático das veredas comparadas com limites do CONAMA para enquadramento nos padrões de qualidade para corpos d'água, com os limites máximos de enquadramento para classe 3 .

\begin{tabular}{|c|c|c|c|}
\hline \multirow[b]{2}{*}{ Atributos } & \multicolumn{2}{|c|}{ Superfícies } & \multirow{2}{*}{$\begin{array}{l}\text { Limites } \\
\text { Classe } 3\end{array}$} \\
\hline & Chapada & Bauru & \\
\hline Odor & Inodoro & Inodoro & VA* \\
\hline Cor $(\mathrm{uH})$ & 586,67 & 235,6 & 75 \\
\hline Condutividade $(\mu$ mho $)$ & 8,55 & 38,17 & $\ldots$ \\
\hline Turbidez (uT) & 13,16 & 36,1 & 100 \\
\hline $\mathrm{pH}$ & 5,4 & 6 & $6,0-9,0$ \\
\hline Acidez total (ppm de $\mathrm{CaCO}_{3}$ ) & 10,8 & 10,08 & $\ldots$. \\
\hline Alcalinidade total $\left(\mathrm{ppm}\right.$ de $\left.\mathrm{CaCO}_{3}\right)$ & 6,09 & 4,3 & $\ldots$. \\
\hline Dureza total (ppm de $\left.\mathrm{CaCO}_{3}\right)$ & 26,76 & 30,97 & $\ldots$. \\
\hline Sólidos totais $\left(\mathrm{mg} \mathrm{L}^{-1}\right)$ & 2035 & 1402 & $\ldots$. \\
\hline Gás carbônico (ppm de $\mathrm{CO}_{2}$ livre) & 8,87 & 8,87 & $\ldots$. \\
\hline Oxigênio consumido $\left(\mathrm{mg} \mathrm{L}^{-1}\right)$ & 5,57 & 3,37 & $\ldots$ \\
\hline Cálcio $\left(\mathrm{mg} \mathrm{L}^{-1}\right)$ & 0 & 2,73 & $\ldots$. \\
\hline Magnésio (mg L $\left.{ }^{-1}\right)$ & 0,01 & 1,41 & $\ldots$. \\
\hline Cobre $\left(\mathrm{mg} \mathrm{L}^{-1}\right)$ & 0 & 0,03 & 0,5 \\
\hline Zinco $\left(\mathrm{mg} \mathrm{L}^{-1}\right)$ & 0 & 0,03 & 5 \\
\hline Ferro solúvel $\left(\mathrm{mg} \mathrm{L}^{-1}\right)$ & 0,7 & 1,3 & 5 \\
\hline Manganês (mg L $\left.{ }^{-1}\right)$ & 0 & 0,03 & 0,5 \\
\hline Cloretos $\left(\mathrm{mg} \mathrm{L}^{-1}\right)$ & 0,08 & 1,33 & 250 \\
\hline Flúor $\left(\mathrm{mg} \mathrm{L}^{-1}\right)$ & 0 & 0 & 1,4 \\
\hline
\end{tabular}

*virtualmente ausente; (....) não considerado para classificação. 
TABELA 2 - Atributos relacionados com a cor da água do lençol freático das veredas.

\begin{tabular}{|c|c|c|c|c|}
\hline \multirow[b]{2}{*}{ Ambientes } & \multicolumn{4}{|c|}{ Parâmetros } \\
\hline & $\begin{array}{l}\text { Cor } \\
(\mathbf{u H})\end{array}$ & $\begin{array}{c}\text { Oxigênio consumido } \\
\left(\mathrm{mg} \mathrm{L}^{-1}\right)\end{array}$ & $\begin{array}{l}\text { Matéria orgânica do solo } \\
\left(\mathrm{g} \mathrm{kg}^{-1}\right)\end{array}$ & $\begin{array}{l}\text { Ferro na água } \\
\left(\mathrm{mg} \mathrm{L}^{-1}\right)\end{array}$ \\
\hline Chapada & 586,67 & 5,57 & 505,8 & 0,7 \\
\hline Bauru & 235,6 & 3,37 & 131,7 & 1,3 \\
\hline
\end{tabular}

Um alto teor de matéria orgânica dissolvida na água, em contato com outras substâncias, pode representar riscos para a saúde humana, uma vez que a simples exposição dessas águas a derivados clorados gera trihalometanos, compostos cancerígenos (ABDEL-RAHMAN, 1982).

Os valores de turbidez encontrados são baixos e menores nas veredas da Chapada. A água possui baixo valor de dureza, sendo considerada água mole para ambos os ambientes. Nas veredas da Chapada, a água é ácida, de caráter agressivo, que se atenua nas veredas do Bauru.

O ferro está presente em quantidades expressivas na água das veredas, principalmente nas do Bauru. Concentrações elevadas de ferro na água causam alteração da cor, sabor e odor, inviabilizando o seu consumo (CETESB, 1977).

Os teores de cálcio, magnésio, cobre, zinco, ferro e manganês na água do lençol freático, assim como no solo, foram maiores nas veredas do Bauru que nas da Chapada, sugerindo uma maior reserva mineral neste ambiente. Outro fato que pode contribuir para a maior concentração destes elementos na água das veredas do Bauru é a menor capacidade dos solos desta superfície em reter nutrientes, quando comparados com os da Chapada, em função daqueles solos possuírem uma textura menos argilosa. Segundo Couto et al. (1985), Latossolos de textura média sofrem uma lixiviação intensa, quando a precipitação efetiva é alta. Ainda que poucos, os nutrientes liberados dos minerais primários são levados para os cursos d'água, enriquecendo os mesmos.

As veredas representam uma importante fonte de água de fácil acesso à maioria das propriedades rurais na região. Por esta razão, são de extrema importância para as comunidades rurais que ali sobrevivem.

A água deste ambiente é de boa qualidade, segundo os moradores, porém, em condições de represamento torna-se ferruginosa, tomando uma coloração avermelhada e apresentando lodo.

Ao longo das veredas tanto do Bauru como da Chapada, frequientemente se observam pequenas represas.
A água das veredas da Chapada é utilizada para limpeza do maquinário agrícola e para aplicação de agroquímicos. A água também é utilizada para dessedentação animal, de forma mais expressiva nas veredas do Bauru, reflexo da forte aptidão à pecuária deste ambiente. Outra importante alavanca da utilização crescente das águas dos ambientes de vereda se concentra na construção de tanques de piscicultura.

$\mathrm{O}$ volume d'água desses ambientes varia entre a época das águas e das secas, podendo ser reduzido em $40 \%$ nas veredas da Chapada e em até $60 \%$ do volume total nas do Bauru no período seco.

A irrigação com utilização da água de veredas é uma realidade que toma vulto entre os produtores rurais, que se aproveitam da fácil disponibilidade da mesma e a utilizam em diversas culturas. A maioria dos proprietários de terra tem a intenção de aproveitar o ambiente de veredas em suas propriedades para construir represas, com a finalidade de irrigação de suas culturas.

\section{Uso dos solos das veredas}

As entrevistas informais com os agricultores bem como as observações de campo, permitem interpretações com relação ao uso destes ambientes que aparecem a seguir.

A comunidade vegetal não foi caracterizada no presente estudo, entretanto, observou-se que além de uma maior densidade de veredas na superfície do Bauru (Figura 3), estas apresentam-se com uma vegetação mais densa e com maior número de espécies arbóreas e arbustivas, próximo à rede de drenagem, quando comparadas com as veredas da Chapada. Dentre os fatores que possivelmente estão contribuindo para este comportamento diferenciado quanto à estrutura dessas comunidades vegetais, pode-se citar a relativa melhor drenagem dos solos das veredas do Bauru, favorecendo maior oxigenação e propiciando a sobrevivência de espécies menos adaptadas a ambientes hidromórficos. De maneira geral, a vegetação das veredas é praticamente 
desconhecida pela comunidade rural. É dada importância somente ao capim nativo, que serve de alimentação para o gado.

Os proprietários rurais da superfície da Chapada utilizam o solo de suas propriedades em agricultura intensiva e tecnificada. Os solos das veredas, nestas propriedades, na maioria das vezes não são utilizados, sendo considerados pelos proprietários como áreas de preservação. Pequena parte dos produtores utiliza parte da área das veredas como pastagem nativa para o gado. Segundo os produtores rurais, a alta umidade dos solos de veredas dificulta o trabalho mecanizado, inviabilizando sua utilização.

Nas propriedades rurais da superfície do Arenito Bauru, o principal uso do solo é com pastagem nativa, destinada a pecuária de corte extensiva. Em algumas propriedades, principalmente nas mais próximas ao setor urbano, a pastagem começa a ser substituída pela agricultura intensiva. Em pequenas propriedades rurais, próximas ao setor urbano, os solos das veredas são utilizados para o cultivo de mandioca, abóbora, vagem, quiabo, jiló, inhame, batata-doce, milho, feijão, cana e capim. Neste caso, as veredas são drenadas. No presente estudo, problemas de subsidência dos solos foram constatados durante as entrevistas.

\section{CONCLUSÕES}

As veredas, em razão da influência do lençol freático, possuem solos hidromórficos em toda a sua extensão transversal, os quais se diferenciam em Organossolos Mésicos, Gleissolos Melânicos e Gleissolos Háplicos. Nas veredas da Chapada, há maior diversidade de solos, havendo nesta superfície o predomínio de Organossolo Mésico no terço inferior, Gleissolo Melânico no terço médio e Gleissolo Háplico no terço superior das veredas. Nas veredas do Bauru, predominam Gleissolos em todos os segmentos da paisagem.

Nas veredas, do terço superior em direção ao inferior, piora a drenagem e aumentam os teores de argila, de matéria orgânica e a fertilidade natural dos solos.

Os solos das veredas das Chapadas apresentam pior drenagem, textura mais argilosa, maior teor de matéria orgânica e menor fertilidade natural que os solos das veredas do Bauru.

A água das veredas foi enquadrada na classe 4, principalmente devido aos altos teores de matéria orgânica dos solos, tendo como principais usos, a lavagem de maquinários, aplicação de pesticidas e irrigação, representando grande risco de contaminação ambiental, ao passo que a água das veredas do Bauru têm como principal uso a dessedentação do gado.

Os solos das veredas da Chapada não são utilizados para atividade agrícola, pois estas áreas são consideradas de preservação e apresentam, como forte limitação para o cultivo de plantas anuais, o excesso de umidade, que dificulta a utilização de maquinário agrícola. Os solos das veredas do Bauru apresentam como uso predominante, a pastagem nativa destinada à pecuária de corte extensiva, que exerce papel fundamental na alimentação do gado durante a época seca.

A cor preta ou cinzenta dos solos das veredas é um atributo de fácil identificação no campo e pode ser utilizada para delimitar tais ambientes de preservação permanente.

\section{REFERÊNCIAS BIBLIOGRÁFICAS}

ABDEL-RAHMAN, M. S. The presence of trihalomethanes in soft drinks. Journal of Applied Toxicology, New York, v. 2, n. 3, p. 162-166, 1982.

AB'SABER, A. N. A organização natural das paisagens inter e subtropicais brasileiras. In: SIMPÓSIO SOBRE O CERRADO, 3., 1962, São Paulo. Anais... São Paulo: USP, 1971. p. 1-11.

ALVAREZ, V. H.; NOVAIS, R. F.; BARROS, N. F.; CANTARUTTI, R. B.; LOPES, A. S. Interpretação dos resultados de análises de solos. In: RIBEIRO, A. C.; GUIMARÃES, P. T. G.; ALVAREZ, V. H. (Eds.). Recomendação para o uso de corretivos e fertilizantes em Minas Gerais: $5^{\text {a }}$ aproximação. Viçosa: CFSEMG, 1999. p. 25-32.

AMARAL, A. F. Estrutura comunitária da vegetação, em uma seção transversal de vereda da reserva vegetal do CCPIU. 1999. 54 f. Monografia (Bacharelado em Biologia) - Universidade Federal de Uberlândia, Uberlândia, 1999.

AMERICAN PUBLIC HEALTH ASSOCIATION. Standard methods for examination of water and wastewater. 17. ed. Washington, 1989. No page.

BACCARO, C. A. D. As unidades geomorfológicas e a erosão nos chapadões do município de Uberlândia. Sociedade \& Natureza, Uberlândia, v. 6, n. 11/12, p. 19-33, jan./dez. 1994.

BARBOSA, G. Relevo. In: BDMG. Diagnóstico da economia mineira: espaço natural. Belo Horizonte, 1967. v. 2, p. 69-108. 
BOA VENTURA, R. S. Contribuição aos estudos sobre evolução das veredas. In: ENCONTRO NACIONAL DE GEÓGRAFOS, 3., 1978, Fortaleza. Anais... Fortaleza: AGB/ UFC, 1978.

CARVALHO, P. G. S. As veredas e sua importância no domínio dos cerrados. Informe Agropecuário, Belo Horizonte, v. 15, n. 168, p. 54-56, 1991.

COMPANHIA DE TECNOLOGIA DE SANEAMENTO AMBIENTAL - CETESB. Poluição, proteção e usos múltiplos de represas. São Paulo: E. Blúcher, 1977. p. 185.

COMPANHIA DE TECNOLOGIA DE SANEAMENTO AMBIENTAL - CETESB. Guia de coleta e preservação de amostras de água. São Paulo, 1988. 155 p.

CORRÊA, G. F. Les microreliefs "Murundus" et leur environment pedologique dans l' Oest du Minas Gerais: reion du Plateau Central Bresilien. 1989. These (Docteur) L'Université de Nancy I. France, France, 1989.

COUTO, E. G.; RESENDE, M.; REZENDE, S. B. Terra ardendo. Ciência Hoje, Rio de Janeiro, v. 3, n. 16, p. 48-57, jan./fev. 1985.

DAY, P. R. Particle fractionation and particle-size analysis. In: BLACK, C. A. Methods of soil analysis. Madison: ASA, 1965. v. 1, p. 545-566.

EMPRESA BRASILEIRA DE PESQUISA AGROPECUÁRIA. Serviço Nacional de Levantamento e Conservação de Solos. Mapa esquemático das regiões Norte, Meio Norte e Centro-Oeste do Brasil. Rio de Janeiro, 1975. 535 p. (Boletim de pesquisa, 17).

EMPRESA BRASILEIRA DE PESQUISA AGROPECUÁRIA. Serviço Nacional de Levantamento e Conservação de Solos. Levantamento exploratório-reconhecimento de solos da margem esquerda do Rio São Francisco, estado da Bahia. Recife, 1976. 404 p. (Boletim de técnico, 38).

EMPRESA BRASILEIRA DE PESQUISA AGROPECUÁRIA. Serviço Nacional de Levantamento e Conservação de Solos. Levantamento de reconhecimento dos solos do Distrito Federal. Rio de Janeiro, 1978. 455 p. (Boletim de pesquisa, 53).
EMPRESA BRASILEIRA DE PESQUISA AGROPECUÁRIA. Serviço Nacional de Levantamento e Conservação de Solos. Manual de métodos de análise de solo. Rio de Janeiro, 1979.

EMPRESA BRASILEIRA DE PESQUISA AGROPECUÁRIA. Serviço Nacional de Levantamento e Conservação de Solos. Levantamento de média intensidade dos solos e avaliação da aptidão agrícola das terras do Triângulo Mineiro. Rio de Janeiro, 1982.526 p. (Boletim de pesquisa, 1).

EMPRESA BRASILEIRA DE PESQUISA AGROPECUÁRIA. Serviço Nacional de Levantamento e Conservação de Solos. Levantamento exploratórioreconhecimento dos solos do Estado do Maranhão. Rio de Janeiro, 1986. 964 p. (Boletim de pesquisa, 35).

EMPRESA BRASILEIRA DE PESQUISA AGROPECUÁRIA. Serviço Nacional de Levantamento e Conservação de Solos. Manual de métodos de análise de solo. Rio de Janeiro, 1997.

EMPRESA BRASILEIRA DE PESQUISA AGROPECUÁRIA. Centro Nacional de Pesquisa de Solos. Sistema brasileiro de classificação de solos. Brasília, DF; Rio de Janeiro, 1999. 412 p.

EMPRESA DE PESQUISA AGROPECUÁRIA DE MINAS GERAIS. Levantamento de reconhecimento detalhado dos solos da área sob influência do reservatório de Três Marias. Belo Horizonte, 1978. 236 p. (Boletim técnico SNLCS, 57).

GRAndE, M. A.; CURI, N.; QUAGGIO, J. A. Disponibilidade de fósforo pelos extratores Mehlich e resina, em solos cultivados com arroz irrigado. Revista Brasileira de Ciência do Solo, Campinas, v. 10, n. 1, p. 4550, 1986.

KLUG, H. P.; ALEXANDER, L. E. X-ray diffraction procedures for polycrystalline and amorphous materials. New York: J. Wiley \& Sons, 1974. 716 p.

LEMOS, R. C.; SANTOS, R. D. Manual de descrição e coleta de solo no campo. 3. ed. Campinas: Sociedade Brasileira de Ciência do Solo, 1996. 83 p. 
LIMA, S. C. As veredas do Ribeirão Panga no Triângulo Mineiro e a evolução da paisagem. 1996. 260 f. Tese (Doutorado em Geografia Física) - Universidade de São Paulo, São Paulo, 1996.

MELO, D. R. de. As veredas nos planaltos do Noroeste Mineiro: caracterizações pedológicas e os aspectos morfológicos e evolutivos. 1992. 218 f. Dissertação (Mestrado em Geografia) - Universidade do Estado de São Paulo, Rio Claro, 1992.

MELO, D. R. de. Contribuição ao estudo geomorfológico de veredas: região de Pirapora, MG. 1978. 54 f. Monografia (Graduação em Geografia) Universidade Federal de Minas Gerais, Belo Horizonte, 1978.

RAIJ, B. van; QUAGGIO, J. A.; CANTARELLA, H.; FERREIRA, M. E.; LOPES, A. S.; BATAGLIA, O. C. Análises de solo para fins de fertilidade. Campinas: Fundação Cargil, 1987. 170 p.

RESENDE, M. Mineralogy, chemistry, morphology and geomorphology of some soils of the central plateau of Brazil. 1976. 237 f. Thesis (Ph.D.) - Purdue University, West Lafayette, 1976.
RESENDE, M. Sistema de classificação da aptidão agrícola dos solos (FAO/brasileiro) para algumas culturas específicas, necessidades e sugestões para desenvolvimento. Informe Agropecuário, Belo Horizonte, v. 9, n. 105, p. 83-89, set. 1983.

RESENDE, M.; CURI, N.; REZENDE, S. B.; CORRÊA, G. F. Pedologia: base para distinção de ambientes. 3. ed. Viçosa: NEPUT, 1999. 338 p.

RESENDE, M.; REZENDE, S. B.; CARMO, D. N. Roteiro pedológico I. Viçosa: UFV, 1985. Mimeog.

RHUE, R. Quaternary landscapes in Iowa. Ames: Iowa State University, 1969.

RIBEIRO, J. F.; WALTER, B. M. T. Fitofisionomias do bioma cerrado. In: SANO, M. S.; ALMEIDA, S. P. (Eds.). Cerrado: ambiente e flora. Planaltina: EMBRAPA-CPAC, 1998. 556 p.

SPERLING, M. von. Introdução da qualidade das águas e ao tratamento de esgotos: princípios do tratamento biológico em águas residuárias. 2. ed. Belo Horizonte: UFMG, 1996. v. 1, 243 p.

VETTORI, L. Métodos de análises de solo. Rio de Janeiro: Ministério da Agricultura, Equipe de Pedologia e Fertilidade do Solo, 1969. 24 p. (Boletim técnico 7). 